\title{
Pelvic pain due to intrauterine retention of fetal bone after second trimester medical termination of pregnancy: a rare case report
}

\author{
Meena Salvi*, Madhubala Chauhan
}

Department of Obstetrics and Gynecology, RNT Medical College, Udaipur, Rajasthan, India

Received: 20 September 2017

Accepted: 27 October 2017

\section{*Correspondence:}

Dr. Meena Salvi,

E-mail: meenabhati2007@gmail.com

Copyright: (C) the author(s), publisher and licensee Medip Academy. This is an open-access article distributed under the terms of the Creative Commons Attribution Non-Commercial License, which permits unrestricted non-commercial use, distribution, and reproduction in any medium, provided the original work is properly cited.

\begin{abstract}
Intrauterine retention of fetal bone is a rare complication of second trimester termination of pregnancy. These patients may present with abnormal uterine bleeding, dysmenorrhea and secondary infertility. In this case pelvic pain was the only symptom. A 32-year-old woman with history of second trimester medical termination of pregnancy was examined. Pelvic ultrasound revealed retained products of conception. After surgical evacuation, intrauterine retained fetal bone was identified to be the cause of pelvic pain. In patients with history of second trimester abortion, cause of pelvic pain should be properly evaluated.
\end{abstract}

Keywords: Intrauterine retention of fetal bone, Medical termination of pregnancy (MTP), Pelvic pain, Pelvic inflammatory disease (PID), Retained products of conception (RPOCs)

\section{INTRODUCTION}

Intrauterine retention of fetal bone is a rare complication or subsequent to second trimester and MTP. The reported incidence of retained fetal bone is $0.15 \%$ among diagnostic hysteroscopies. ${ }^{1}$ These patients may present with pelvic pain, dysmenorrhea, abnormal uterine bleeding and infertility. ${ }^{2}$

Retained fetal bone may cause pelvic pain in rare case regardless of time interval after second trimester medical termination of pregnancy (MTP). Such patients should primarily be evaluated by detailed history, examination and pelvic ultrasound (USG). The treatment is simply removal of retained intrauterine fetal bone.

\section{CASE REPORT}

A 32-year old multiparous woman was admitted to our Department of Obstetrics and Gynaecology, RNT Medical College, Udaipur with complaints of lower abdominal pain for one month. She had a history of induced second trimester abortion at some private nursing home in her village six months ago. She was married at 20 years of age. She had 3 live female children. Last delivery was 8 years ago. Her menstrual cycles were regular.

She had never been evaluated after MTP. At the time of presentation to our department, she was complaining of pain lower abdomen. On general examination vitals were normal. She was mild anaemic, hemoglobin was 9.8 gm\%. On per abdominal examination tenderness was present in the lower abdomen. On pelvic examination, uterus Retrover ted, Retroflxed, across size, firm mobile, billeted fournics were free. Pelvic ultrasound revealed RPOCS, $14 \times 14 \mathrm{~mm}$ size.

After detailed investigation, she was prepared for surgical evacuation. After I.V. sedation uterine cavity was evacuated with help of suction canula and then sharp curette. On curettage few RPOCS which was hard in 
consistency was felt and removed with difficulty. We were amazed to see it was fetal bone $0.5 \times 2.5 \mathrm{~cm}$ in size, which was removed from uterine cavity. The procedure was done uneventfully. She was discharged in a stable condition next day with proper counselling and advice for contraception and regular follow-up.

\section{DISCUSSION}

Intrauterine retention of fetal bone is a rare complication of second trimester MTP. A rare but significant cause of uterine factor of infertility is retained fetal bones from previous mid-trimester D and E. Apart from secondary infertility, retained fetal bones may also present with irregular bleeding per vaginum, dysmenorrhea, dysparauneia and chronic pelvic pain. ${ }^{3}$ Verma et al reported the case of a 20 year old woman with history of multiple terminations of pregnancy leading to chronic pelvic pain which got relieved after hysteroscopic removal of the intrauterine fetal bone. ${ }^{4}$

Gupta N et al reported a case of 35-year-old woman with history of lower abdominal pain and amenorrhea for 2 months following a surgical second trimester abortion. ${ }^{2}$ Ultrasound detected bright intrauterine echoes suggestive of retained fetal skull and bones in the uterine cavity. On hysteroscopy, a number of bones including skull bones were found adherent to the right and left uterine walls above the isthmus. Bones were removed with difficulty from the uterus by dilatation and curettage. The largest piece was $2 \times 0.5 \mathrm{~cm}$.

Chowhan AK et al reported a case of secondary infertility of six years duration with pelvic pain and dysfunctional uterine bleeding and concluded that the patient had retained fetal bony fragments during the second trimester MTP leading to secondary infertility. ${ }^{1}$ Removal of the fragments by curettage relieved her of pelvic pain symptoms and regularized her menstrual cycles.

Srofenyoh EK et al reported a case of chronic pelvic pain, dysmenorrhea after 16 weeks MTP, pelvic ultrasound suggested 3 highly echogenic substances in the uterine cavity. ${ }^{3}$ These 3 pieces of small bones, each about $2 \mathrm{~cm}$ long, were retrieved from the uterine cavity by dilatation and evacuation.

Chowhan $\mathrm{AK}$ et al in mid trimester abortion, instrumentation tends to detach the fetal head and the skull may have to be crushed. ${ }^{1}$ The retention of a bony structure in the endometrial cavity or ossification of the endometrium may play the role of an intrauterine contraceptive device (IUCD) in preventing conception. Intrauterine retention of fetal bone should be remembered in patients with pelvic pain, DUB or infertility following second trimester MTP. Diagnosis can be made by ultrasound, x-ray pelvic or hysteroscopy. Our patient was asymptomatic after removal of retained bone by dilatation and curettage, confirming it as the cause of pelvic pain.

This case report emphasizes that mild complaints like pelvic pain should be taken into consideration regardless of time interval after second trimester MTP. Detailed history including past history, clinical examination and importance of ultrasound to rule out the presence of intrauterine fetal bone to prevent major future complications like pelvic inflammatory device (PID), irregular bleeding and infertility. Moon et al reported 11 cases in which retained fragments of fetal bones after second trimester abortion contributed to secondary infertility. ${ }^{5}$ Taylor et al in a study of a patient reported secondary infertility in severe, pelvic pain in one and passage of bony fragments in one. ${ }^{6}$

\section{CONCLUSION}

Intrauterine retention of fetal bones may cause pelvic pain after second trimester MTP. Possibility of retained RPOC's should be considered in cases especially with pelvic pain, regardless of time interval after MTP, otherwise it can lead to PID which may cause infertility. MTP must be performed by trained personnel at Institutional level with follow-up and family planning counselling.

\section{Funding: No funding sources \\ Conflict of interest: None declared \\ Ethical approval: Not required}

\section{REFERENCES}

1. Chowhan AK, Rukmangadha N, Babu SKV, Patnayak $\mathrm{R}$, Phaneendra BV, Devi VM. Retained intrauterine fetal bones: a rare cause of secondary infertility leading to diagnostic dilemma. J Clin Sci Res. 2012;1:103-5.

2. Nupur G, Neeta S, Suneeta M, Renu M, Vatsla D. Intrauterine retention of fetal bones: an unusual cause of pelvic pain. J Obstet Gynecol India. 2009;59(6):584-5.

3. Srofenyoh EK, Addison M, Dortey B, Kuffour PA. Intrauterine retained fetal bones as a cause of secondary infertility. Ghana Med J. 2006;40(3):105-9.

4. Verma U, Chong D, Perez I, Medina C. Fetal bones retained in the uterine cavity as a rare cause of chronic pelvic pain: a case report. J Reprod Med 2004;49:853-5.

5. Moon HS, Park YH, Kwon HY, Hong SH, Kim SK. Iatrogenic secondary infertility caused by residual intrauterine fetal bone after midtrimester abortion. Am J Obstet Gynecol. 1997;176:369-70.

6. Taylor PJ, Hamou J, Mencaglia L. Hysteroscopic detection of heterotopic intrauterine bone formation. $\mathbf{J}$ Reprod Med. 1988;33:337-9.

Cite this article as: Salvi M, Chauhan M. Pelvic pain due to intrauterine retention of fetal bone after second trimester medical termination of pregnancy (MTP): a rare case report. Int J Reprod Contracept Obstet Gynecol 2017;6:5646-7. 